\title{
Interações sociais em sala de aula: o ensino de Língua Portuguesa
}

"Pensar a sala de aula como um espaço de nascimento de leitores /escritores é propor que nela se instalem a interação e a palavra."

(Mary Julia Martins Dietzsch e Maria Alice Setúbal S. e Silva).

\section{Resumo}

Este artigo tem por finalidade abordar o ensino de Língua Portuguesa - a escrita, a leitura e a gramática - dentro de uma concepção de linguagem como mediação e como um processo de ação que é social.

\section{Abstract}

This article has the objective to discuss the teaching of the Portuguese Language - the writing, the reading and the grammar - from a language conception as mediation and a social process as well.

\section{1 - Concepções de linguagem}

Se o professor considerar o seu trabalho pedagógico como um espaço interativo e de partilha, mediado pela linguagem, a reflexão sobre sua própria ação assume um significado especial. No estabelecimento dessas ações, o professor, especialmente o de Língua Portuguesa, e os alunos necessitam ter clareza dos seus objetivos e saber o que pretendem alcançar. Assim, o professor precisa conhecer sua concepção de linguagem, pois é ela que irá fundamentar a sua ação pedagógica. A prática escolar, em que a relação professor/ aluno e aluno/aluno é mediada pela palavra, não pode ser vista como algo neutro, desvinculado da realidade.

Assumir que qualquer proposta metodológica é articulada a uma concepção de mundo e de educação é perceber, de alguma forma, as diferentes concepções de linguagem que estão presentes no cotidiano da sala de aula. Nos estudos sobre a linguagem ao longo da história é possível considerar, de uma forma ampla, três concepções a respeito desse sistema de significação ${ }^{1}$.

1. "Linguagem como expressão do pensamento".

Nessa concepção, ela é percebida como sistema idealizado, no qual as leis do pensamento é que regem as leis da linguagem. Temos o exemplo de pessoas que, não tendo uma linguagem mais "requintada”, não pensam corretamente. A expressão é construída no interior da mente, sendo a exteriorização a sua tradução. Essa concepção de linguagem pressupõe que há uma forma correta de falar e escrever, estabelecida a partir de regras a serem seguidas. São estas regras "que, em geral, aparecem consubstanciadas nos chamados estudos lingüísticos tradicionais que resultam no que se tem chamado de gramática normativa ou tradicional" (TRAVAGLIA, 1995, p.21).

2. "Linguagem enquanto instrumento de comunicação".

Essa concepção está ligada à teoria da comunicação. A língua é entendida como conjunto de símbolos que combinam entre si regras próprias e que é capaz de transmitir uma mensagem. $\mathrm{O}$ domínio desse código possibilita melhores condições da comunicação. A linguagem é perce-

\footnotetext{
* Doutoranda em Comunicação e Semiótica. Mestre em Educação: Didática. Especialista em Educação e Saúde Pública. Licenciada em Pedagogia. Professora do curso de Pedagogia das Faculdades Integradas "Campos Salles".

${ }^{1}$ Autores que tratam deste tema (concepções de linguagem): GERALDI (1984), TRAVAGLIA (1996), BRITTO (1991).
} 
bida como fenômeno externo, que não faz parte da natureza humana, servindo como canal para a comunicação entre as pessoas.

3. "Linguagem como forma de interação".

Mais do que um instrumento de comunicação e de expressão de pensamento, a linguagem é percebida aqui como um lugar de interação humana, construída socialmente e marcada pelo seu caráter interlocutivo. Nessa concepção, a linguagem não é percebida, simplesmente, como um código para transmitir informações ou uma forma de exteriorizar o pensamento. Quando utilizamos a linguagem estamos interagindo, atuando sobre o outro, influenciando-o e sendo influenciados. A comunicação é percebida como um processo no qual as pessoas envolvidas procuram negociar sentidos, tentando criar significados partilhados. Não é só "passar" informações, mas compartilhá-las. Assim, a linguagem é a possibilidade de interação comunicativa buscando a produção e construção de significados, de sentidos, enfim, de elaboração de conhecimento.

Estabelecendo um paralelo entre essas concepções, teríamos as correntes dos estudos lingüísticos: a gramática tradicional, o estruturalismo e a lingüística da enunciação.

Segundo Geraldi (1984), quando perguntamos o "para que" ensinamos a língua, estamos definindo uma concepção de linguagem e uma postura de educação. Dependendo da concepção de linguagem envolvida nas atividades pedagógicas, teremos posturas educacionais diferentes. "Uma diferente concepção de linguagem constrói não só uma nova metodologia, mas principalmente um 'novo conteúdo' de ensino" (GERALDI,1984, p.46).

Dentro dessas concepções, como podemos estabelecer a relação professor-aluno? Analisando as duas primeiras, percebemos que o professor centraliza o processo de ensino; a linguagem é vista como um instrumento de comunicação, sendo usada para dar informações, em que os aspectos interpretativos são deixados de lado. $\mathrm{O}$ professor coloca-se como o único intérprete, o legítimo, dizendo "o que" e "o como" deve ser dito. Os aspectos formais e estruturais da língua é que são evidenciados.
Já na terceira concepção de linguagem, percebemos que o discurso do professor é um entre os muitos que o rodeiam. Nessa concepção interacional, a linguagem é entendida pelo seu caráter dialógico, onde vários discursos estão presentes e são permitidos. $\mathrm{O}$ professor surge, então, para cumprir um papel de mediador na busca dos diversos sentidos possíveis da linguagem, procurando assimilar e organizar as diferentes falas presentes na sala de aula, incentivando a participação, a iniciativa e a cooperação dos alunos e fazendo respeitar as mais variadas opiniões.

Pelo exposto, pensamos que o ensino da língua começa pela construção de relações adequadas, que permitirã́o uma efetiva interação entre o professor e os alunos; cada um tem seu espaço para se colocar, participar, dialogar, negociar, enfim, constituir-se como sujeito.

Citelli (19.91) ratifica bem o que seria o ensino da língua dentro dessa terceira concepção: "Se o professor pensa o ensino da língua a partir de uma referência interacional (inter/ação), saberá radicalizar o aspecto dialógico e trabalhará o seu discurso como um entre vários, no meio dos quais estarão aqueles dos alunos que vivem experiências culturais diferenciadas, que falam sobre o mundo a partir de lugares múltiplos, que operam variáveis lingüísticas nem sempre afinadas com a do mestre. Posto desse modo, o ensino da língua terá que refletir, necessariamente, a dinâmica do confronto inter e intradiscursivo e não apenas considerar a variável linearmente codificada pela gramática padrão como única a ser valorizada e aplaudida" (p.16).

Procuro delinear uma perspectiva de linguagem, entendida como atividade interacional/social e humana. Ela é o próprio conteúdo de Língua Portuguesa que o professor trabalha em sala de aula. Com isso, enfoco três pontos básicos no ensino de Português: o trabalho com a escrita, o trabalho com a leitura e o estudo da gramática. Para fins meramente didáticos, separo aqui essas práticas. Sei que tais atividades não devem acontecer de forma separada, mas sim interligadas. Uma determinada prática contém as outras e vice-versa.

Dentro da terceira concepção de linguagem 
apresentada, como ficam estabelecidas essas três questões fundamentais no ensino de Língua Portuguesa? $\mathrm{O}$ que seria um professor mediador no trabalho com a leitura/escrita e com a gramática?

\section{O trabalho com o texto}

O conhecimento da linguagem escrita começa muito antes de a criança freqüentar uma escola. A psicogênese da língua escrita ${ }^{2}$ tem mostrado que o processo de alfabetização tem início antes do contato da criança com a $1^{\text {a }}$ série.

Através de revistas, jornais, cartazes, rótulos, televisão etc., a linguagem escrita deve ter chamado a atenção da criança, em maior ou menor grau. Esses contatos com o material escrito levam a criança a formular hipóteses sobre a escrita e a leitura. Porém, essas hipóteses muitas vezes não são percebidas pelo professor, que ainda exige da criança uma visão adulta a respeito da escrita, não percebendo que as hipóteses que a criança vem formulando sobre esse sistema nem sempre coincidem com aquilo que o professor entende por língua escrita e processo de leitura. Esse processo evolui, muda com a idade da criança, sendo difícil estabelecer uma relação direta entre o ensino sistemático (escolar) e essa evolução.

Não pretendo me deter na discussão ampla apresentada na psicolingüística sobre o processo da escrita, uma vez que o meu interesse, neste trabalho, diz respeito às possibilidades de construção de um ambiente em sala de aula que estimule a leitura/escrita, sublinhando o papel do professor nesse ambiente.

No presente estudo, pode-se considerar a estreita relação existente entre o desenvolvimento da linguagem escrita e o ambiente escolar em que ele se desenvolve. O trabalho de Calkins (1989) traz contribuições importantes na construção de um espaço adequado para a produção escrita. Partindo de suas experiências, a autora evidencia a importância da interação social nesse espaço e faz um convite aos professores para que olhem/observem como as crianças escrevem, como ocorre o desenvolvimento da escrita. Nesse olhar aprendemos muito sobre a construção da escrita e como intervir no trabalho dos diferentes alunos. A criança deve ser vista como um ser ativo que produz, que constrói, que interage e que dá pistas para a nossa intervenção. Calkins (1989) ressalta a necessidade de se responder aos primeiros esforços de escrita das crianças como os pais respondem às primeiras tentativas de fala de seus filhos. Ao exemplo da mãe que interpreta e amplia os titubeios iniciais da criança em busca de comunicação, também o professor deve estar atento e atribuir significados às tentativas de seu aluno para se comunicar por meio da escrita. Os textos escritos nesse espaço devem ser lidos, discutidos, reelaborados, ou seja, o professor e os alunos são percebidos como parte integrante do processo de escrita.

Um dos primeiros aspectos a ser considerado diz respeito ao ambiente que se constrói em sala de aula. A sala de aula poderá ser pensada como um lugar em que as crianças tenham a oportunidade de se movimentar com autonomia sob o olhar atento do professor. Um espaço previsível, cuidadosamente planejado, dentro de uma organização, com horários e regras preestabelecidas que permitam as mais diversas interações.

Calkins (1989) considera que os ambientes mais criativos em nossa sociedade não são os mais sofisticados, mas aqueles previsíveis e simples, "uma vez que as interações e o trabalho que se tem a fazer já são, por si sós, complexos e imprevisíveis" (p. 25).

É necessário estabelecer um certo ritmo nesse espaço, propiciando-se um tempo necessário, adequado, para que os alunos possam escrever, reescrever e falar o que escreveram, com os colegas e com o professor. A escrita de um texto não se esgota em um dia e, como sugere Calkins (1989), o estabelecimento de um período para a escrita é importante, pois permite que as crianças

${ }^{2}$ Estamos nos reportando ao trabalho realizado por Emília Ferreiro e Ana Teberosky. 
assumam controle sobre seus próprios processos de escrita. Quando esses alunos conhecem os parâmetros em que estão trabalhando, podem desenvolver estratégias e planos para a elaboração do seu texto.

Assim, após definir o tema a ser trabalhado, cada aluno ou o grupo inicia o primeiro rascunho; a seguir, esse rascunho será lido para a classe, recebendo opiniões e sugestões da professora e dos outros alunos. Tal momento é marcado por perguntas, indagações, sugestões e dúvidas. Essa interação possibilita, muitas vezes, a reelaboração do pensamento do autor e, por sua vez, do texto lido. $\mathrm{O}$ mais relevante desse processo são as possibilidades de troca de idéias, opiniões e conhecimentos entre o autor do texto e os seus leitores.

"Trata-se da escrita sem pressa, com destino e significação, a escrita da vida que vai muito além do atendimento a uma encomenda, ou ao cumprimento de uma obrigação" (DIETZSCH; SILVA, 1994, p. 60).

É, pois, fundamental um espaço onde os que escrevem sejam também leitores e que o texto seja visto como uma obra inacabada que vai se construindo à medida que o escritor interage com os leitores que estão à sua volta.

Um ambiente assim preparado inspirará confiança para a criança se expressar, sem medo nem restrições. $O$ professor, ao trabalhar o grupo, vai procurar construir laços afetivos, aprofundando relações entre os participantes. Isso possibilitará maior abertura, gerando confiabilidade, fazendo com que o aluno assuma sua palavra e se sinta inserido no meio ambiente, contando sempre com o outro na construção de sua escrita/texto.

"Portanto, o mínimo que podemos fazer é ajudar os jovens a verem a escrita como um meio seguro, um lugar para a exploração e descoberta; necessitamos ajudá-los a ver a aula de redação como uma comunidade de apoio" (CALKINS, 1989, p. 129).

Outro aspecto lembrado por Calkins (1989), diz respeito à relação que o professor estabelece com a escrita e a leitura, ou seja, se o professor não demonstrar entusiasmo, interesse e comprometimento, provavelmente, os alunos também não o farão. Se o ler e escrever são dois aconteci- mentos importantes nas nossas vidas, as pessoas que irão mediatizar esses momentos são também de fundamental importância. $\bigcirc$ professor, além de ser o mediador do texto, criará oportunidades para que outros escritos entrem na sala de aula. É fundamental que se leia muito, oferecendo-se à classe uma gama variável de textos. Segundo a autora: "O papel do professor é fornecer o tempo, materiais e estrutura para toda esta escrita/diálogo/ leituralescuta e resposta, ampliando o que as crianças são capazes de fazer. Os professores ajudam pelo fornecimento de muitas razões funcionais para a escrita" (1989, p. 62).

Outro aspecto a ser considerado no trabalho com a escrita diz respeito à avaliação. Compreendemos esse processo em que o professor ficará atento ao progresso que o aluno está apresentando e observando quais têm sido suas dificuldades e avanços. Essa avaliação servirá de base para as ações do professor e dos alunos, à medida que trará dados referentes aos trabalhos realizados. Dentro de uma visão socioconstrutivista, na qual o aluno tem papel ativo na construção de seu conhecimento, o professor não deverá avaliar apenas o trabalho realizado em momentos determinados, mas, sim, dentro do próprio caminho percorrido pelo aluno, no qual os possíveis erros possam ser percebidos, muitas vezes, como avanços. Nesse sentido, os erros são hipóteses de trabalho que o ser humano vai estabelecendo quando se depara com os problemas. São tentativas e ações a serem consideradas, reveladas e dirimidas, para que o aluno construa o seu próprio conhecimento.

A produção escrita não deve ser percebida como um mero instrumento de aferição de regras gramaticais, mas, antes, como um momento no qual os alunos possam assumir os textos, registrando-os. Quando assumimos nosso discurso, estamos nos constituindo como sujeitos, construindo nossa consciência, enfim, estamos fazendo parte da humanidade. A própria "consciência dos sujeitos forma-se neste universo de discurso e é deles que cada um extrai, em função das interlocuções de que vai participando, um amplo sistema de referências no qual, interpretando os recursos expres- 
sivos, constrói sua compreensão do mundo" (GERALDI, 1991, p. 31).

A visão de mundo que cada indivíduo tem é única; porém, podemos e devemos compartilhar nossas impressões, no sentido até de reformulá-las. A produção escrita pode ser vista como um desses momentos, ou seja, um espaço no qual imprimo idéias, as compartilho e, posteriormente, posso até reformulá-las.

\section{3- O trabalho com a leitura}

(...) lê-se para entender o mundo, para viver melhor. Em nossa cultura, quanto mais abrangente a concepção de mundo e de vida, mais intensamente se lê, numa espiral quase sem fim, que pode e deve começar na escola, mas não pode (nem costuma) encerrar-se nela (Marisa Lajolo - Do mundo da leitura para a leitura do mundo).

Segundo Martins (1996), de maneira geral, podemos separar as concepções sobre leitura em duas correntes: a leitura como uma decodificação mecânica de signos lingüísticos, sendo um mecanismo de decifração a ser adquirido, ou como processo de compreensão abrangente e complexo que envolve aspectos sensoriais, emocionais, intelectuais, fisiológicos, neurológicos, culturais, econômicos e políticos. Dentro dessa concepção, o leitor não utiliza só a sua capacidade de transformar sinais gráficos em sonoros, mais do que isso, ele usa os conhecimentos adquiridos ao longo da sua vivência e de sua própria experiência de vida. Nesse sentido, o contexto de vida do leitor, as pessoas que fazem parte do seu convívio "passam a ter influência apreciável em seu desempenho na leitura. Isso porque o dar sentido a um texto implica sempre levar em conta a situação desse texto e de seu leitor" (MARTINS, 1996, p. 33).

Ao realizarmos determinada leitura, estamos interagindo não só com o escritor, mas também com outros textos já lidos, ou seja, quando lemos, colocamos em ação os nossos próprios conceitos, valores, intenções, crenças, enfim, nosso conhecimento. Dentro de uma concepção interacional de lin- guagem, a leitura é percebida como um processo de interlocução entre o leitor e o autor.

No processo de busca do sentido do texto, compartilhamos nossas interpretações, e é através desse diálogo que conseguimos perceber os diversos significados desse conteúdo. Nesse aspecto, o papel do professor torna-se fundamental, porque se espera que ele seja um leitor amadurecido, ou seja, que tenha intimidade com muitos textos. Segundo Lajolo (1993), "leitor maduro é aquele para quem cada nova leitura desloca e altera o significado de tudo o que ele já leu, tornando mais profunda sua compreensão dos livros, das gentes e da vida" (p. 53).

Assim, o professor poderá, muitas vezes, servir de mediador entre o texto e o leitor e, nessa conversação, colocará perguntas, fará comentários, fornecerá estratégias que possam enriquecer o diálogo de seu aluno com o texto.

Durante a leitura é interessante que o professor e os seus alunos estabeleçam objetivos e propósitos nas leituras que estão sendo realizadas. Quando lemos apenas porque outra pessoa nos manda ler, porque somos obrigados a dar uma resposta a outrem, como acontece freqüentemente na escola, estamos apenas exercendo atividades mecânicas que pouco têm a ver com significado e sentido (KLEIMAN, 1989).

Desse modo, faz-se necessário estabelecer objetivos e expectativas na leitura, pois é com base neles que o leitor formula suas hipóteses e, ao consegui-las, passará a analisá-las para confirmar, refutar ou revisá-las.

Entre os fatores relacionados que fazem parte da compreensão da atividade da leitura, destaco a importância da intertextualidade, ou seja, a relação dialógica que um determinado texto estabelece com outro, como fator relevante ao entendimento e à interpretação dos sentidos a serem alcançados pelo leitor. Segundo Vigner (1988), a intertextualidade está presente quando: "todo o texto que, pela relação que estabelece com textos anteriores ou com o texto geral, dissemina em si fragmentos de sentido já conhecidos pelo leitor, desde a citação direta até a mais elaborada reescritura. Ler significa aí perceber este trabalho de 
manipulação sobre os textos originais e interpretálos" (p. 34).

O diálogo entre os textos pode acontecer de forma explícita ou implícita. Na intertextualidade explícita é mantida alguma característica do texto original ou, até mesmo, faz-se referência direta a esse texto básico, deixando transparecer a relação entre ambos. Na intertextualidade implícita, as referências são "mais sutis".

Segundo Vieira (1988), um determinado texto pode dialogar com outros textos de diversas formas: estilizando, imitando, parodiando ou polemizando. $\mathrm{O}$ fenômeno da intertextualidade deve ser percebido por quem trabalha a leitura e tem a preocupação com a formação do leitor. Quanto mais contato a criança tiver com textos diferentes, mais elementos de referência terá à sua disposição e se intensificará sua experiência intertextual.

Na recepção dos textos, o professor deve ter a preocupação de reconhecer de quem é a voz que fala e que valores estão sendo relacionados. $\mathrm{Na}$ prática, porém, sabemos que é muito difícil esse procedimento e quase nunca conseguimos saber de quem é a responsabilidade do texto enunciado, se ele é original ou derivado. Todavia, a leitura assídua e constante nos permite reconhecer a correlação existente entre os textos, para que possamos entendê-los e até certo ponto classificá-los (VIEIRA, 1988).

Assim, o professor pode e deve trabalhar as relações que os textos estabelecem entre si, percebendo a relação dialógica existente. É nesse sentido que se faz necessária no contexto escolar a presença de uma ampla diversidade de tipologia textual e de autores. Não só histórias, mas também textos científicos, jornalísticos e biográficos devem fazer parte da leitura em sala de aula. Parece que a èscola esqueceu que as crianças também se interessam por outros assuntos, não devendo existir apenas uma leitura específica para a criança, o jovem, o adulto...

Ler um determinado texto não é só decodificar sinais gráficos em sonoros; é a partir disso ser capaz de atribuir significação ao texto, conseguir relacioná-lo a todos os outros textos significativos para cada um, reconhecer nele o tipo de leitura que seu autor pretendia, e o leitor, dono da própria vontade, pode entregar-se a essa leitura, ou rebelar-se contra ela, propondo outra não prevista ou esperada, como pode acontecer na escola (LAJOLO, 1993).

A prática de leitura é um processo de descoberta, atribuição de sentidos e de significados, os quais deverão ser construídos, socialmente, o que implica estabelecer um diálogo com o texto, com o autor e também com os outros leitores.

\section{4 - A prática de análise lingüística}

"A gramática é um assunto que parece ter pouca utilidade prática. Ao contrário de outras matérias escolares, não ensina novas habilidades à criança, pois esta já conjuga e declina antes de entrar na escola. Já se chegou até mesmo a dizer que o ensino da gramática na escola poderia ser abolido. Podemos replicar que a nossa análise mostrou claramente que o estudo da gramática é de grande importância para o desenvolvimento mental da criança. (...) a criança domina, de fato, a gramática da sua língua materna muito antes de entrar na escola, mas esse domínio é inconsciente, adquirido de forma puramente estrutural, tal como a composição fonética das palavras... Ela pode não adquirir novas formas gramaticais ou sintáticas na escola, mas, graças ao aprendizado da gramática e da escrita, realmente torna-se consciente do que está fazendo e aprende a usar suas habilidades conscientemente". (VYGOTSKY, 1995, p. 87).

A criança, antes mesmo de entrar na escola, já usa e apreende conceitos gramaticais sem que tenha passado por qualquer ensino sistematizado. Assim, podemos afirmar que o estudo da gramática faz parte do conhecimento lingüístico do usuário de qualquer língua. Porém, sabemos que, mesmo a criança sabendo falar, não conhece muitas das formas de construção dessa língua.

Fazendo referência à discussão de que a linguagem foi vista pelo seu caráter interlocutivo, sendo construída coletivamente, como fica a prática de análise lingüística nessa construção?

A gramática, assim como a linguagem, deve ser entendida como um conhecimento adquirido coletivamente, em situações reais de interação ver- 
bal. Contudo, o que tenho observado é que o ensino da gramática é entendido como algo fechado, pronto e estruturado, sendo trabalhado dentro de uma determinada seqüência, através de exercícios de memorização e de repetição, tratados de forma fragmentada, como se não tivessem relação entre si. Essa é uma prática muito presente nos livros didáticos e nas salas de aula.

No entanto, um caminho alternativo para a análise lingüística, nas séries inicias, poderia iniciar-se pela fala e pela produção escrita dos alunos. Assim, o professor poderá coletar dados do processo lingüístico e, de posse desse diagnóstico, traçar suas metas para o ensino da gramática. Nesse sentido, "a gramática deixa de ser imposta e inacessível para ser de todos e os professores deixam de trabalhar com textos e exemplos modelares de língua (oral e escrita) para trabalhar com textos produzidos pelos alunos no sentido de descobrir as suas hipóteses sobre a língua e confrontá-las umas com as outras e com a convenção". (SILVA,1986, p. 69)

Reafirmando essa proposta de trabalho com gramática, Geraldi (1984) sugere que as atividades de análise lingüística devem partir do texto do aluno e, para cada aula, o professor selecionará apenas um problema, procurando estudá-lo. A intenção desse trabalho é partir do erro para a auto-correção. Dentro dessa perspectiva, a metodologia de ensino da gramática deve partir das reais necessidades diagnosticadas no processo de aprendizagem de uma determinada língua, levando o aluno a construir e reconstruir essas regras, de forma contextualizada.

Porém, em séries mais adiantadas, além de ser trabalhado a partir das produções orais ou escritas dos alunos, o ensino da gramática deve ter um espaço para um trabalho mais sistemático, que vá além da produção do aluno para atingir a estrutura e o funcionamento da língua em situações as mais diferenciadas. Como afirma Vygotsky (1995), os conceitos gramaticais devem ser trabalhados na sala de aula, mais especificamente na disciplina de Língua Portuguesa, e a criança deve ter possibilidade de construí-los, buscando sempre a lógica desses conceitos. É o uso da língua a serviço da comunicação, o que é muito diferente de se decorar regras e definições para serem rigidamente cobradas e devolvidas em avaliações.

Tanto o ensino da leitura, como o processo da escrita e o estudo da gramática devem ser vistos como atuações compartilhadas em que as diversas falas, discursos e intenções podem ser negociadas e não apenas entendidas como práticas estanques. A produção de textos pode impregnar-se das leituras e, simultaneamente, o aluno ser convidado e incentivado a observar os aspectos relativos à organização textual.

A escrita, a leitura e a gramática são práticas culturais a serem trabalhadas não de maneira casual. Pelo contrário, o professor precisa estabelecer suas ações, decidindo o que pretende fazer, como fazer e ter clareza do porquê está fazendo. É interessante lembrar que todas essas ações, que fazem parte do cotidiano escolar, são consideradas complexas e estão permeadas de intenções e, nesse sentido, precisam ser planejadas. $O$ trabalho coletivo e a própria construção da proposta pedagógica se fazem necessários, quando percebemos a necessidade de uma organização que envolve a escola e suas diferentes faces e relações.

\section{REFERÊNCIAS BIBLIOGRÁFICAS}

BAKHTIN, Mikhail. Marxismo e Filosofia da linguagem. São Paulo: Hucitec, 1995.

BRITO, Luiz Percival Leme. Fugindo da norma. Campinas: Átomo, 1991.

CALKINS, Lucy McCormick. A arte de ensinar a escrever: o desenvolvimento do discurso escrito. Porto Alegre: Artes Médicas, 1989.

CITELLI, Adilson Odair. O ensino de linguagem verbal: em torno do planejamento. In: MARTINS, Maria Helena. Questões de linguagem. São Paulo: Contexto, 1991.

DAVIS, Claudia; SILVA, Maria Alice Setúbal; ESPÓSITO, Yara. Papel e valor das interações sociais em sala de aula. Caderno de Pesquisa, São Paulo, n.71, p. 49-54, nov. 1989. 
DIETZSCH, Mary J. M.; SILVA, Maria A.S. Itinerantes e itinerários na busca da palavra. Caderno de Pesquisa, São Paulo, n.88, p.55-63, fev. 1994.

FERREIRO, Emilia; TEBEROSKY, Ana. Psicogênese da língua escrita. Porto Alegre: Artes Médicas, 1991.

GERALDI, J.W. Concepções de linguagem e ensino da língua. In: GERALDI, J.W. (Org). O texto na sala de aula. Cascavel, Paraná: Assoeste/UNICAMP, 1984.

. Portos de passagem: linguagem, trabalho e ensino. São Paulo: Martins Fontes, 1991.

KLEIMAN, Angela B. Leitura: ensino e pesquisa. São Paulo: Pontes,1989.

- Oficina de leitura: teoria e prática. Campinas: Universidade Estadual de Campinas, 1993.

LAJOLO, M. O texto não é pretexto. In: ZILBERMAN, Regina (Org.) Leitura em crise na escola. Porto Alegre: Mercado Aberto, 1993.

. Do mundo da leitura para a leitura do mundo. São Paulo: Ática, 1994.

LEITE, Lígia Chiappini M.; MARQUES, Regina M.H. Ao pé do texto na sala de aula. In: ZILBERMAN, Regina (Org.). Leitura em crise na escola. Porto Alegre: Mercado Aberto, 1993.

LOPES, Harry Vieira. A prática do Português no $1^{\circ}$ grau: objetivos, conteúdos, metodologia e avaliação. In: MURRIE, Zuleika de Felice (Org.). Universos da palavra. São Paulo: Iglu, 1995.

MARTINS, M. H. O que é leitura. São Paulo: Brasiliense, 1996.

MURRIE, Zuleika de F. (Org.). O ensino de Português do primeiro grau à universidade. São Paulo: Contexto, 1992.

OLIVEIRA, M. K. de. Vygotsky: aprendizado e desenvolvimento: processo sócio-histórico. São Paulo: Scipione, 1993.

SILVA, Lilian L. M. da. (Org.). O ensino de Lingua Portuguesa no primeiro grau. São Paulo: Atual, 1986.

TRAVAGLIA, Luiz Carlos. Gramática e interação: uma proposta para o ensino de gramática no $1^{\circ}$ e e $2^{\circ}$ graus. São Paulo: Cortez, 1996.

VIEIRA, Yara F. Recepção ativa de textos: uma forma de diálogo. In.: Subsídios à proposta curricular de Língua Portuguesa para o $1^{\circ}$ e $2^{\circ}$ graus. São Paulo: SE/CENP, 1988.

VIGNER, Gerald. Intertextualidade, norma e legibilidade. In: GALVES, C. O texto, leitura e escrita. Campinas: Pontes, 1988. VYGOTSKY, L.S. A formação social da mente. São Paulo: Martins Fontes, 1994.

. Pensamento e linguagem. São Paulo: Martins Fontes, 1995. 